\title{
A systematic review of outcomes after salvage abdominoperineal resection for persistent or recurrent anal squamous cell cancer
}

Gary Ko, Anisha Sarkari, Shaila J. Merchant, Sunil V. Patel

BACKGROUND: Squamous cell carcinoma of the anus (SCCA) is typically treated with chemoradiation. Up to $30 \%$ of patients with SCCA will require a salvage abdominoperineal resection (APR) for persistent or recurrent disease.

Although salvage surgery is common, there is little published evidence summarizing long term outcomes

OBJECTIVE: To assess cancer related outcomes in patients with persistent (PD) and recurrent SCCA (RD).

ASSESSED OUTCOMES: Overall survival (OS), disease free survival (DFS), and locoregional recurrence or metastatic disease.

STUDY DESIGN: Systematic review.

Search of MEDLINE and

EMBASE using MESH terms

200 studies included

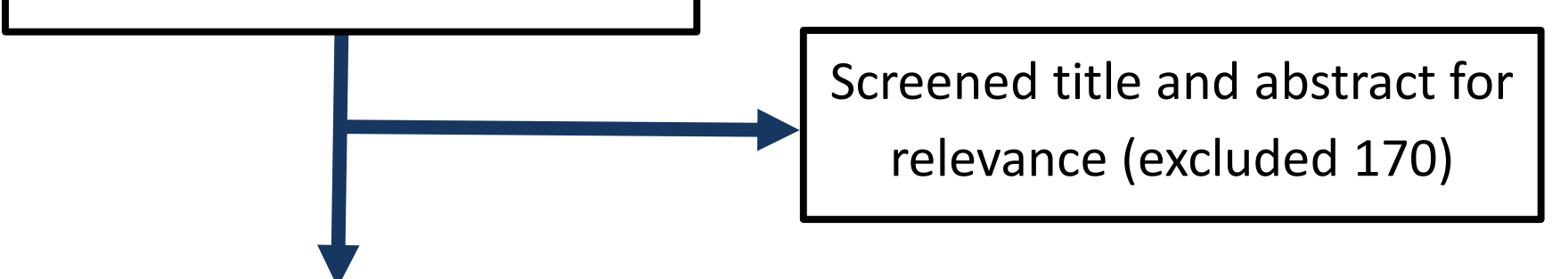

Screened full text for

relevance (30 studies)

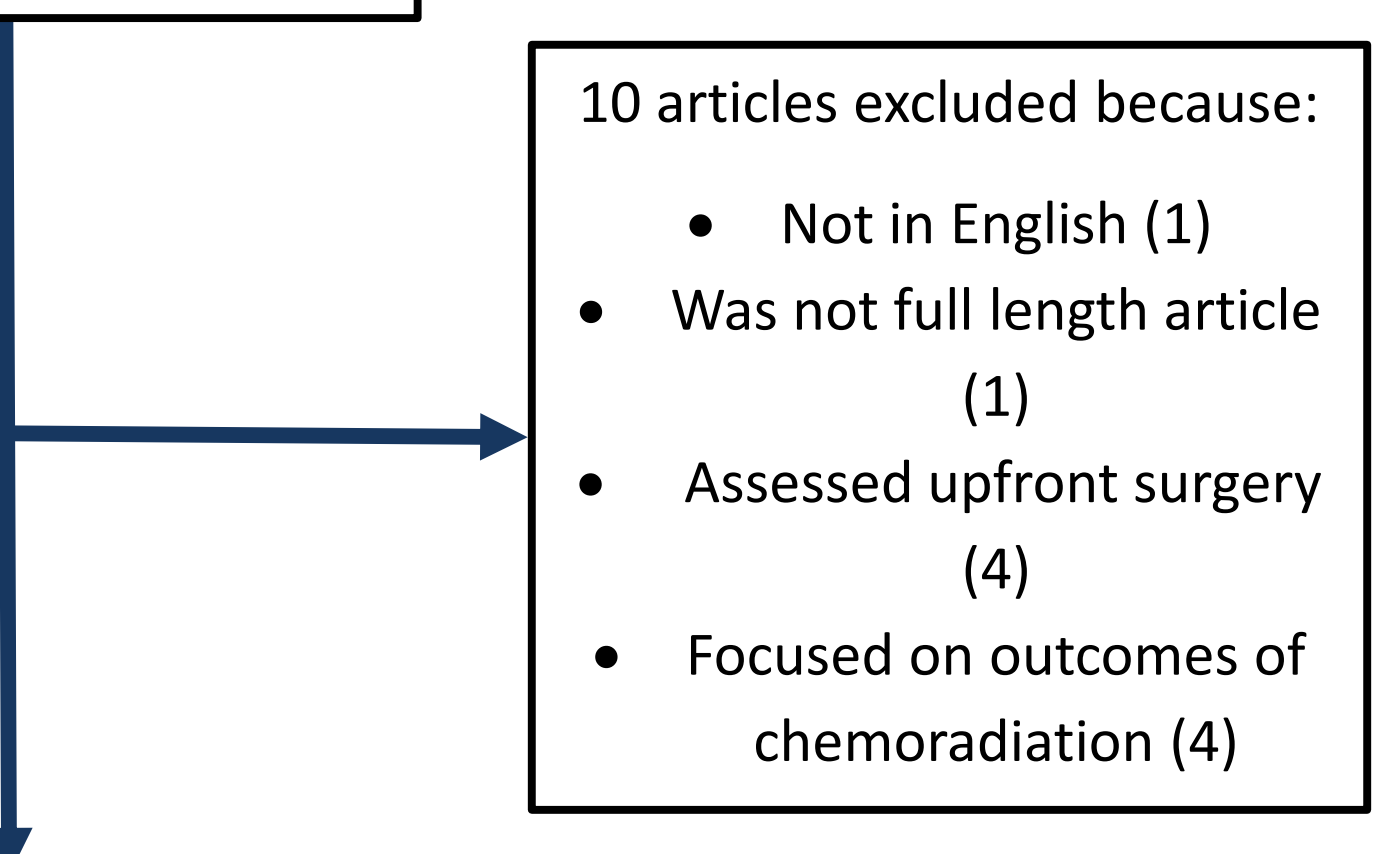

20 studies included for

review

\section{RESULTS:}

- 20 observational, case series studies (year of publication: 19942016).

- Study Size $=9-111$ patients (Median 31.5).

- 10 studies included both HIV and non-HIV patients, but did not analyse the outcomes separately.

- Inconsistent chemotherapy regimens (5FU + MMC, 5FU + Cisplatin, 5FU + Bleomycin/Carboplatin).
- Surveillance protocols were inconsistent (Anoscopy, CT, MRI).

- Median follow-up was 33 months following salvage surgery.

- Persistent disease typically considered if $<6$ months from completion of chemoradiation (14 of 18 with a definition).

\begin{tabular}{|c|c|c|c|}
\hline & Persistent Disease & Recurrent Disease & All \\
\hline $\begin{array}{l}\text { Time to } \\
\text { Surgery }\end{array}$ & $\begin{array}{l}2.8 \text { months } \\
\text { (IQR } 2.6-2.8)\end{array}$ & $\begin{array}{c}25.6 \text { months } \\
\text { (IQR 23.5 - 27.6) }\end{array}$ & -- \\
\hline $\begin{array}{c}\text { Wound } \\
\text { Complications }\end{array}$ & NR Separately & NR Separately & $\begin{array}{c}45.0 \% \\
\text { (IQR } 18.1-59.0 \%)\end{array}$ \\
\hline $\begin{array}{c}\text { Perioperative } \\
\text { Mortality }\end{array}$ & NR Separately & NR Separately & $\begin{array}{c}0 \% \\
\text { (IQR } 0-2 \%)\end{array}$ \\
\hline $\begin{array}{c}5 \text { Year Overall } \\
\text { Survival }\end{array}$ & $\begin{array}{c}46.0 \% \\
\text { (IQR 32.5-54.2\%) }\end{array}$ & $\begin{array}{c}36.0 \% \\
\text { (IQR } 14.0-60.9 \%)\end{array}$ & $\begin{array}{c}41.5 \% \\
\text { (IQR } 32.3-53.1 \%)\end{array}$ \\
\hline $\begin{array}{l}5 \text { Year Disease } \\
\text { Free Survival }\end{array}$ & NR Separately & NR Separately & $\begin{array}{c}44.0 \% \\
\text { (IQR } 29.8-48.6 \%)\end{array}$ \\
\hline $\begin{array}{l}\text { Local Regional } \\
\text { Recurrence }\end{array}$ & NR Separately & NR Separately & $\begin{array}{c}39.8 \% \\
\text { (IQR 34.8-64.8\%) }\end{array}$ \\
\hline $\begin{array}{l}\text { Metastatic } \\
\text { Disease }\end{array}$ & NR Separately & NR Separately & $\begin{array}{c}15.0 \% \\
\text { (IQR } 6.7-30.0 \%)\end{array}$ \\
\hline
\end{tabular}

- Median time to recurrence after salvage APR was 9.2 months (IQR $8.6-11.3)$.

- The most common site of metastatic disease was the liver. Other sites included bone, lung, and brain.

- Chemotherapy was used to treat locoregional recurrence and metastatic disease after salvage APR. Surgery was used to treat nodal recurrence.

- Median survival after recurrence following salvage APR was 21 months (IQR 13 - 35).

CONCLUSIONS: Our review summarizes the best evidence for outcomes following salvage APR for patients with persistent or recurrent SCCA. The evidence is limited by the quality of included studies, as many were single center case series.

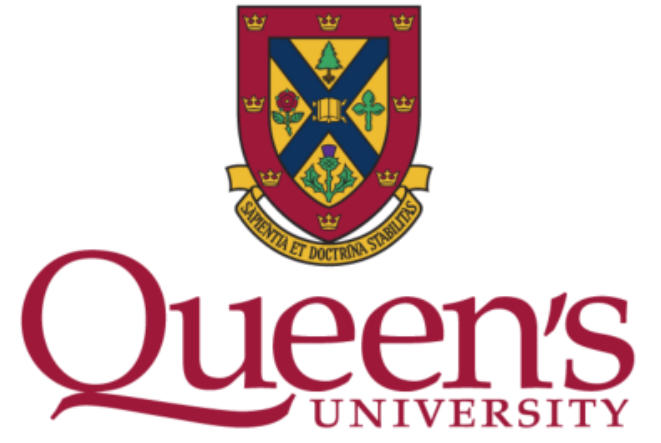

Kingston Health Sciences Centre

Centre des sciences de la santé de Kingston

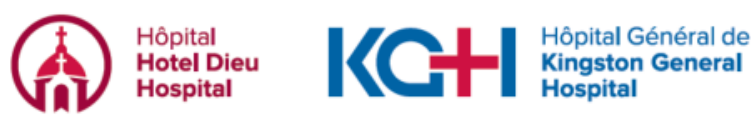

